\title{
Stupéfiants et conduite automobile - les actions réalisées en Allemagne
}

\section{Drugs of abuse and driving : legal conditions and law enforcement in Germany}

Manfred R. MOELLER

\section{$R E ́ S U M E ́$}

En août 1998, une nouvelle législation ( $\$ 24 a$ StVG) a été instituée en Allemagne sanctionnant les conducteurs suspectés de conduire après consommation de certaines substances illicites. Ces substances, listées dans une annexe de la loi, sont : amphétamine, MDMA, MDE, cannabis, cocaïne, héroine et morphine (le cannabis par le THC, l'héroüne par la morphine, la cocaine par la benzoylecgonine). Selon la loi, la présence de l'une de ces substances quelque soit la concentration sanguine observée constitue la preuve que la sujet est sous influence (tolérance zéro). En novembre 2002, la Grenzwertkommission a recommandé des seuils analytiques pour les substances listées précédement. Cette nouvelle loi a conduit à une augmentation très importante des sanctions applicables pour la conduite sous influence de drogues (DUID). De plus, la conduite sous influence est sanctionnée comme un acte criminel selon le code pénal (§316, § 315c StGB).

\section{MOTS-CLÉS}

Stupéfiants, conduite automobile, infraction administrative, infraction criminelle.

\section{SUMMARY}

In August 1998 a new law (\$24a StVG) became effective in Germany sanctioning people suspected of driving after the consumption of certain illicit drugs. These drugs, listed in an appendix to the law, are: amphetamine, MDMA, MDE, cannabis, cocaine, heroin, and morphine (cannabis detected as THC, heroin as morphine, cocaine as benzoylecgonine). According to the law, the presence of any of these drugs in any concentration found in the blood of a subject is evidence of his/her being under the influence (zero-tolerance). In November 2002, the Grenzwertkommission recommended cut-offs for the above listed substances. This new law has led to a dramatic increase of sanctions for driving under the influence of drugs (DUID). In addition, impaired driving is sanctioned as criminal, according to the penal code (\$316, $\S 315 c$ St $G B$ ).

\section{KEY-WORDS}

drugs of abuse, driving, list of substances, administrative offence, criminal offence. 
The legislation about alcohol and driving in Germany differentiates two kinds of offences : administrative, according to § 24a Street Traffic Law (StVG), with blood alcohol concentration between $0.05 \%$ and $0.11 \%$ and criminal, according to $\S \S 316,315 \mathrm{c}$ penal code (StGB), when the blood alcohol concentration is above $0.11 \%$ ( the legal limit in Germany). In the latter case, unfitness to drive is automatically proven, without ( $\S 316$ ), or with concrete endangering a person or things of important value, whether or not an accident occured $(\$ 315 \mathrm{c})$. Even below $0.05 \%$, down to $0.03 \%$ it can be a criminal offen$c e$, if an accident happened or any other severe traffic violation occurred.

The same situation exists with drugs. However, there are no legal limits for driving under the influence of drugs of abuse or pharmaceuticals (DUID). If an unfitness to drive can be proven, it is a criminal offence with the same fines, license revocation for 6 months to two years, fine up to 360 daily rates*), one year prison ( $\$ 316$ ), fine up to 360 daily rated, up to five years prison $(\$ 315 \mathrm{c})$, after the first incidence. Since 1998 a new law has come into force, which bans any concentration of certain drugs of abuse in blood (zero limit) as an administrative offence with a one to three months driving ban and a fine up to $300 €$ after the first incidence. Repeated violations lead to higher fines.

The banned drugs are : amphetamine, MDMA, MDE, cannabis, cocaine, heroin, and morphine. The corresponding analytes are amphetamine, MDMA, MDE, Tetrahydrocannabinol, Benzoylecgonine, and morphine. They are listed in an appendix to the law. The prohibition excludes substances that have been consumed in accordance with medical prescription.

The synopsis of the two laws is shown in Fig.1. In case of an administrative offence, the scope of investigations is limited to the drugs, which are listed in the appendix, including alcohol. In criminal offences all psychoactive drugs must be screened for. In both cases, mandatory blood testing can be enforced. Urine tests, however, cannot be enforced, because of the perceived significant risk of bodily harm (in this case, "force" implies the use of a catheter), and the law does not provide any sanctions if the person refuses.

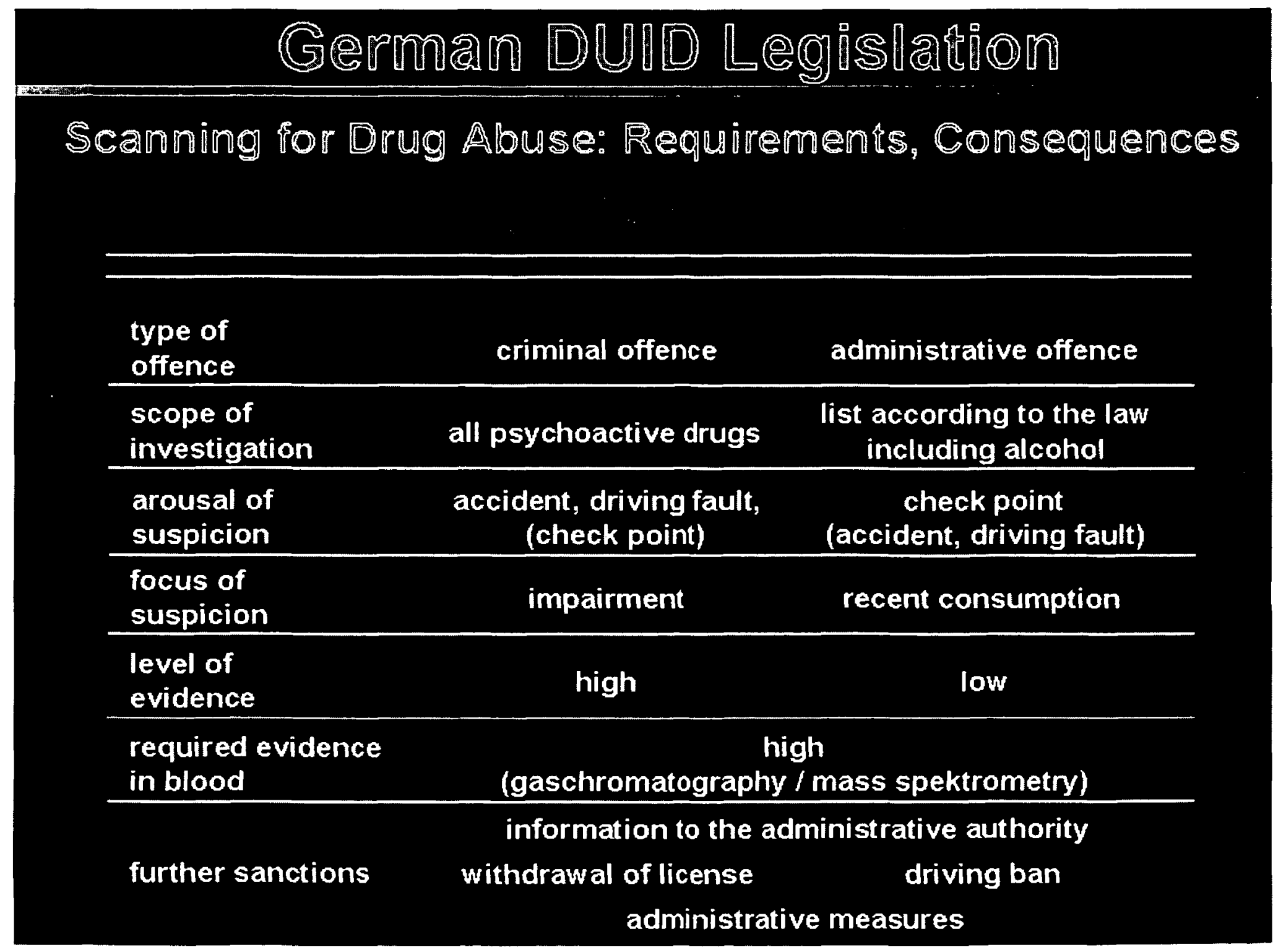

Figure 1 : Synopsis of administrative and criminal offences.

\footnotetext{
*) a daily rate is $1 / 30$ of the monthly income of the subject, e.g. $€ 600$ monthly income means a daily rate of $€ 20$, a daily rate of $€ 100$ corresponds to a monthly income of $€ 3000$.
} 
At checkpoints the police officers identify drivers mostly in cases of administrative offences. This comes from the focus of suspicion. Investigations according to $\S \S 316$, 315 c ("criminal offence") are made after accidents, severe driving faults, or when a subject shows visible signs of impairment, e. g. extremely slow reaction, but also strong psychophysical deficits like disorientation, motor coordination impairment, confusion, unsteady walk, etc. Offences against the administrative law are already fulfilled when recent drug consumption can be assessed (red conjunctiva, slow pupil reaction to light, delayed reaction, sleepiness). The level of evidence must be high in criminal offences. For administrative offences, where the sanctions are much lower, the level of evidence can be less. However, the determination of the drugs in blood must be of the same high quality in both cases, requiring gas chromatography-mass spectrometry as gold standard. Further sanction is revocation of the driver's license and a driving ban for one to three months respectively.

To effectively fulfil the legislative intent, the police officers who control drivers must be trained to recognize subjects driving under the influence of drugs. "Drug recognition in road traffic", a training program initiated by the Federal Highway Research Institute (BASt), has been available to police training schools since September 1997. The program aims to enable police officers to recognize people driving under the influence of drugs and/or pharmaceutical products more reliably.

It is currently in use in ten of the sixteen states of Germany. The program has been developed on the basis of the American DRE program, but with major modifications because of the differences in laws (rights of police officers, evidence in court), technical procedures (mandatory blood sampling in Germany) and drug panorama. It is a one week training program for "drug experts" (Fig.2) and a second, lower level educational program of two half-days with basic facts for the training of all police officers. The whole program has been translated into Finish and Polish, while parts have been translated into English, Czech and Slovenic. Presently, an updated version in English is in the works. It probably will be available by the end of 2003 .

The heart of the training program is a check list for the police officer (Fig.3), where he/she notes any special observations, symptoms of drug use and signs of impairment. A roaring or stalled engine is not a sign of impairment, neither are bloodshot eyes. But it is a signal for the police officer to look at a driver more closely.

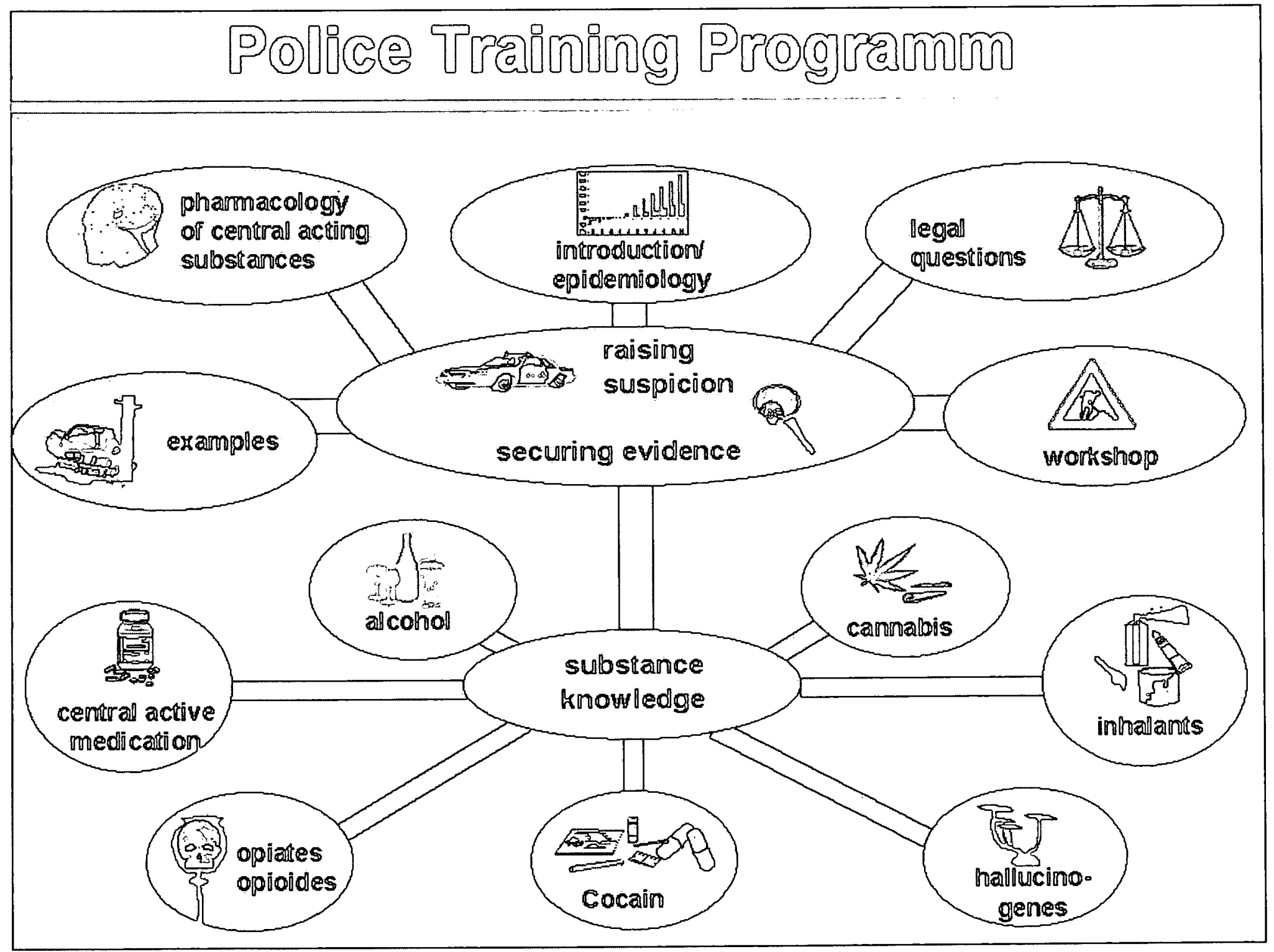

Figure 2 : Training program for police officers to recognize drug use. 


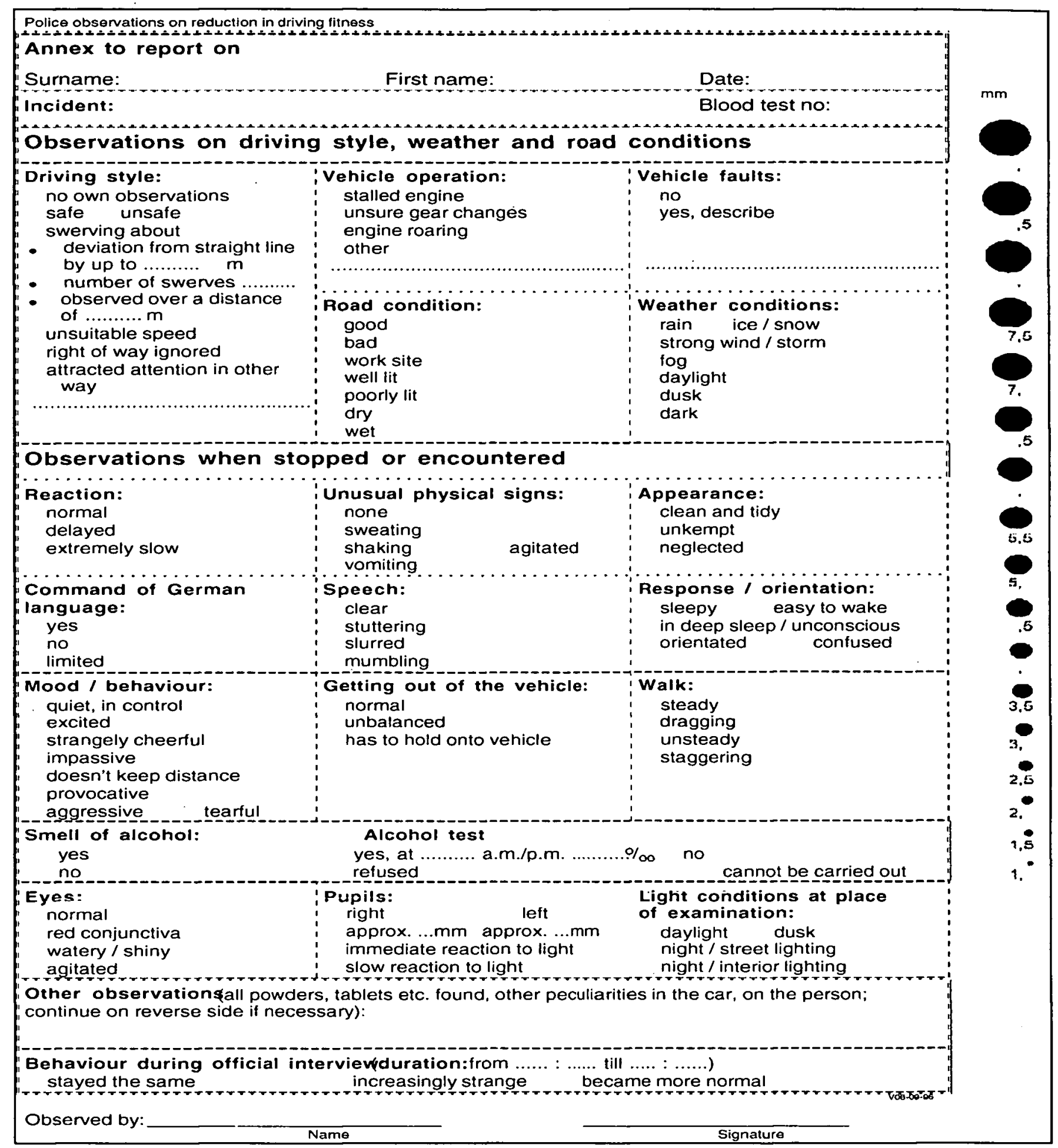

Figure 3 : Checklist for DUID.

After starting a conversation with the driver, and perhaps an onsite test to make the decision about handling the case according to an administrative or a criminal offence, the subject is informed about his rights, a blood sample is taken by a physician and sent to the laboratory, together with a medical report.

The program was introduced in May 1997 in the state of Saarland. In Fig.4, the evolution of the total number of cases up to 2002 is shown. The Institute of Legal Medicine analyses all forensic cases in the State (about 1 million inhabitants). There was a continuous increase in the number of blood samples collected for suspicion of DUID : in 1998 with the new law ( 24 a StVG), 1999 and 2000 with the EU-ROSITA project and further with the state-wide introduction of onsite drug-tests (urine and saliva tests). However, the actual number of accidents under the influence of drugs remained rather constant. This is partly due to the fact that in cases of accidents the police officer, actually on duty at the police station, is called to the scene. The drug recognition experts are working mostly in night shifts at road blocks or at general traffic controls.

In cases of administrative offences ( $\$ 24 \mathrm{a}$ StVG), only the substances, listed in the appendix are checked. The Grenzwertkommission, a group of experts, with members of the German Society of Legal Medicine (DGR), the German Society of Traffic Medicine (DGV), the Society for Toxicological and Forensic Chemistry (GTFCh), the Ministry of Justice, the Ministry of Transportation (BMVBW), and the Federal Highway Traffic Agency (BASt)) decided on cut-offs for these substances in November 2002 (Tab.1). However, the federal states still have not agreed. 


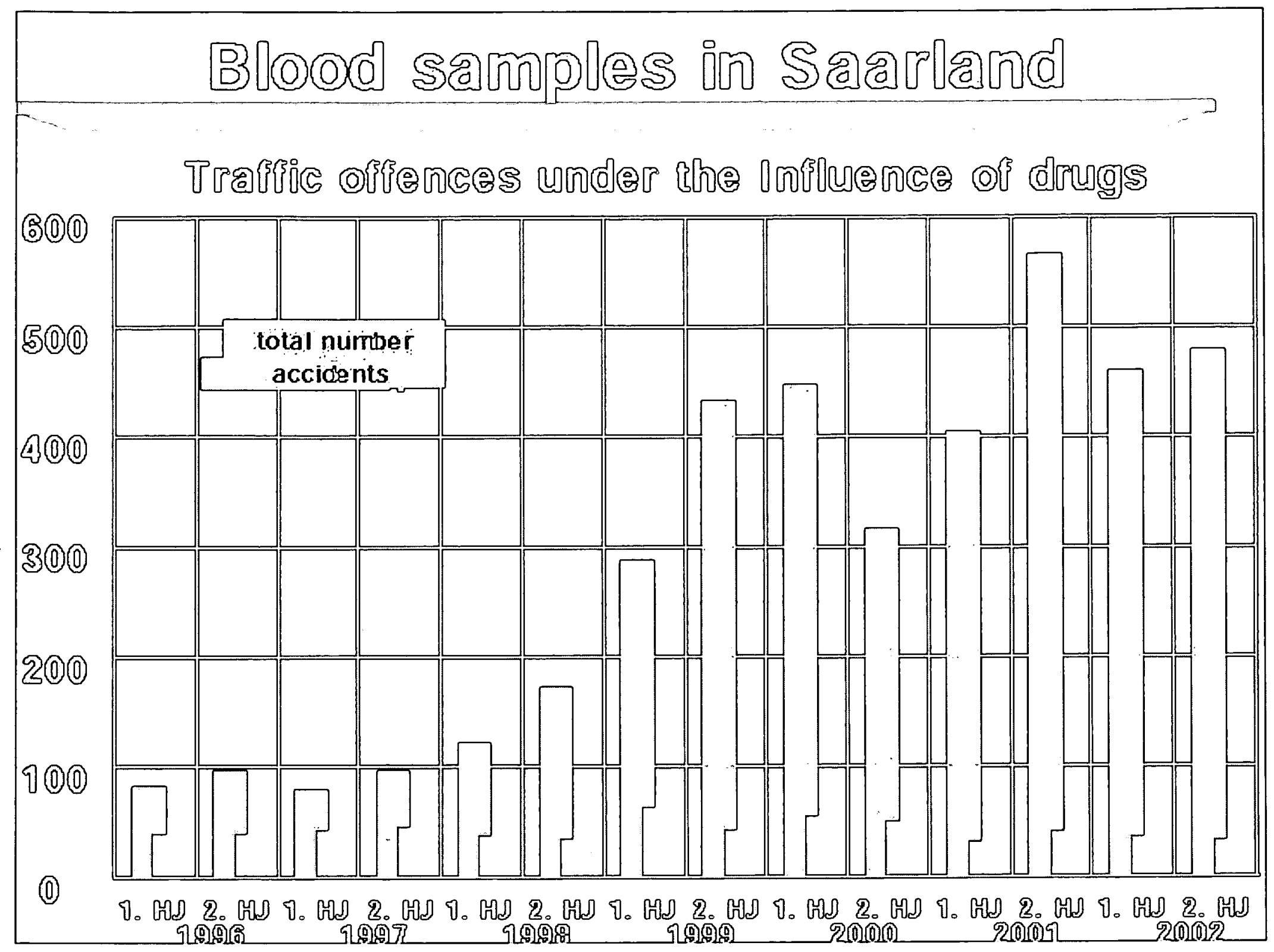

Figure $4:$ Evolution of the number of analysed blood samples in cases of DUID.

The problem in these cases is neither the driving ban of one to three months nor the fine, but the fact, that in positive cases, the conviction is reported to the driver's license authorities. They can then check whether the subject is generally able to drive a car, either by a medico-psychological investigation or a series of urine and/or hair tests, where the subject has to prove that he/she is drug-free. This procedure lasts in general about one year, until the driver gets his license back.

In criminal cases, the well documented observation and convincing statements of the police officer, together with the doctor's report, the results of the toxicological investigation and the toxicological experts opinion are taken into account in court. Here, the decision is made whether it is a criminal offence, according to $\S \S 316,315 \mathrm{c}$ or an administrative offence, according to $\S 24 \mathrm{a}$ StVG. In cases of criminal offences, additionally, beside the conviction, the report to the driver's license authorities is identical to the above described procedure for administrative offences.

In more than $75 \%$, the prosecuting authorities and the court follow in their final decision the initial charges of the police, at least in Saarland (which has a joint border with France). However, the described procedure differs slightly from state to state, according to the federal system in Germany, because police and administrative affairs are under state laws.

\section{Conclusions}

The new "zero-limit" law is a powerful tool for the fight against DUID.

Well trained police officers can recognize and classify symptoms of drug use and signs of impairment.

Well documented protocols will facilitate the decision of the judge in court.

Well documented protocols, and convincing statements of the police officers, when they testify in court, together with the expert opinion, are essentials.

The cut-offs of the Grenzwertkommission for the drugs which are listed in the appendix to § $24 \mathrm{a}$ StVG (table I), have still to be accepted by the German states. 
Annales de Toxicologie Analytique, vol. XV, $\mathrm{n}^{\circ}$ 2, 2003

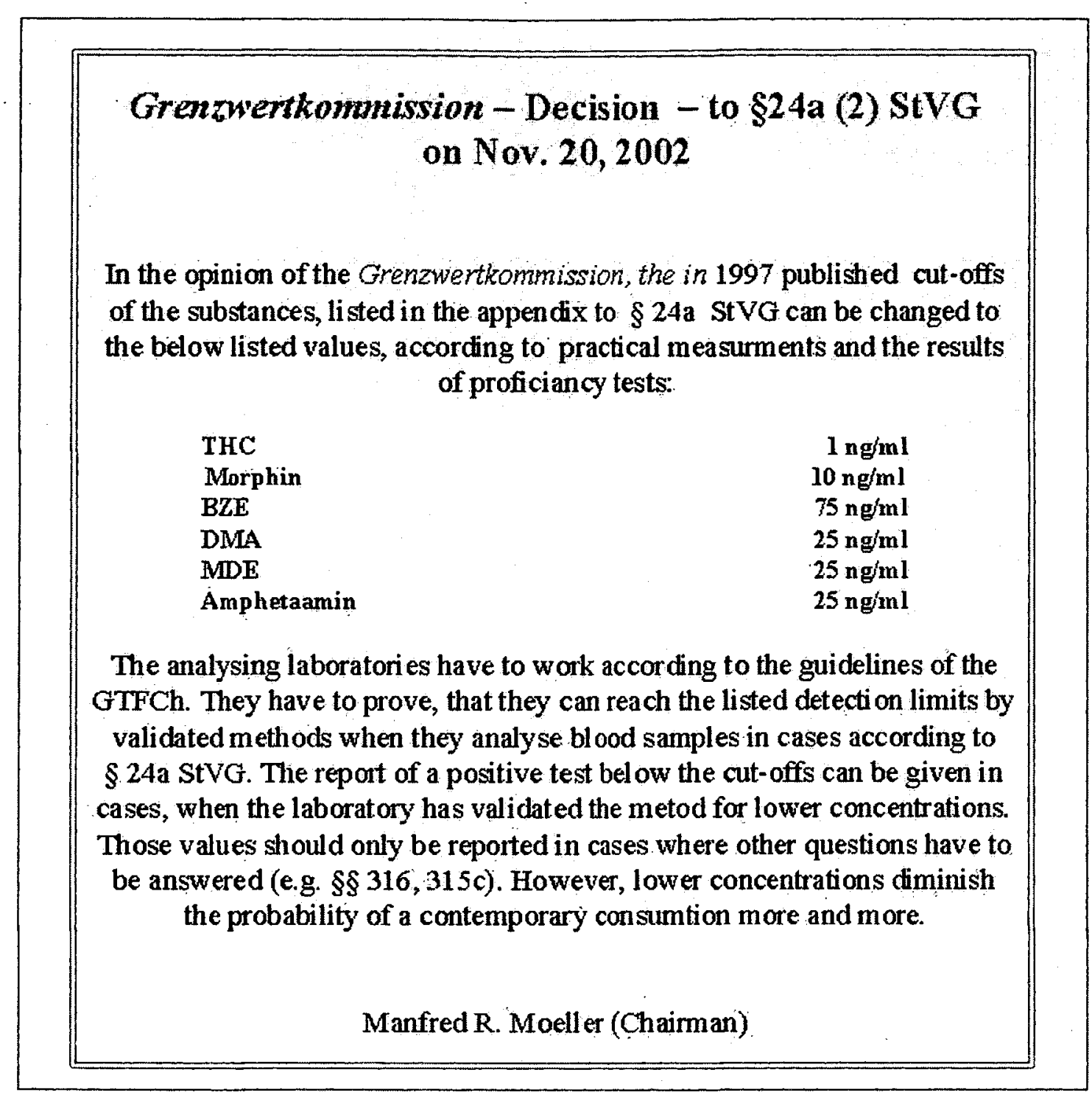

Table I : Cut-off concentrations of drugs of abuse : proposal of the Grenzxertkommission. 